\title{
Standardized Patients in Communication Sciences and DIsorders: Past, Present and Future Directions
}

\author{
Richard I. Zraick \\ Univ. of Central Florida, richard.zraick@ucf.edu \\ DOI: https://doi.org/10.30707/TLCSD4.3/KHSI3441
}

Follow this and additional works at: https://ir.library.illinoisstate.edu/tlcsd

Part of the Communication Sciences and Disorders Commons

\section{Recommended Citation}

Zraick, Richard I. (2020) "Standardized Patients in Communication Sciences and DIsorders: Past, Present and Future Directions," Teaching and Learning in Communication Sciences \& Disorders: Vol. 4: Iss. 3, Article 4.

DOI: https://doi.org/10.30707/TLCSD4.3/KHSI3441

Available at: https://ir.library.illinoisstate.edu/tlcsd/vol4/iss3/4

This Scholarly Teaching is brought to you for free and open access by ISU ReD: Research and eData. It has been accepted for inclusion in Teaching and Learning in Communication Sciences \& Disorders by an authorized editor of ISU ReD: Research and eData. For more information, please contact ISUReD@ilstu.edu. 


\title{
Standardized Patients in Communication Sciences and DIsorders: Past, Present and Future Directions
}

\author{
Abstract \\ Standardized patients (SPs) are increasingly being used with students in the field of communication \\ sciences and disorders (CSD). The purpose of this paper is to describe the use of SPs with CSD students. \\ Challenges to the clinical education of students are described, and a call is made to expand the use of \\ SPs to facilitate student learning of clinical skills and to assess students' clinical competency.

\section{Keywords} \\ Standardized Patients, Healthcare Simulation, Clinical Education, Speech-Language Pathology, Audiology
}




\section{"If we teach today's students as we did yesterday's, we rob them of tomorrow" - John Dewey (1915), Schools of Tomorrow (p. 20)}

The educational model for preparing professionals in communication sciences and disorders (CSD) is one that sees students acquire knowledge about normal and disordered communication in the classroom, and then demonstrate emerging mastery of that knowledge through interactions in the clinical setting. In the United States, this model is typically embodied by four years of undergraduate education, followed by either two years of graduate coursework and clinical practicum (for speech-language pathology students) or four years of graduate coursework and clinical practicum (for audiology students). Sometimes students may acquire clinical skills while undergraduates, but for most, clinical education takes place at the graduate level. Clinical education may take place in a university teaching clinic and/or a variety of externship sites. Regardless of the setting, students are expected to apply what they've learned in the classroom to management of clients/patients in the clinical setting. By successfully completing an accredited graduate program, the assumption is made by employers and licensing boards that the graduate is a professional who is competent to evaluate and treat persons with communication disorders. While this assumption fortunately holds true for the most part, there are several emerging challenges which may threaten this assumption if not addressed at the individual and systems level.

In her seminal 2005 article "Issues and Innovations in Clinical Education," McAllister describes challenges to the clinical education of CSD students. These include: (a) changes in the workplaces of CSD professionals; (b) changes in the education of CSD students; (c) standards required by accrediting bodies, registration/licensing boards and professional associations; (d) continued use of outdated approaches to clinical education; and (e) preparation and support for clinical educators (p.139). The challenges are not mutually exclusive, with workplace changes particularly salient regarding how clinical educators best prepare students to succeed in the workplace. McAllister describes in detail the workplace challenges, which include increased demand on time, changes in the models of practice, higher expectations for new graduates, increased specialization, generic roles, an increasingly part-time workforce, and growth of private practice. In the context of these challenges, clinical educators are also facing challenges such as diversity in student cohorts, growth in number of programs and students, and changes in the nature and scope of professional practice (Polovoy, 2015). As McAllister astutely observes (p. 145), "Workplace pressures on clinical educators, increased student numbers concurrent with decreased placement opportunities, new goals for clinical education, employer expectations of graduates, and the need to prepare students to work in diverse settings and service delivery models, all necessitate for clinical education and supervision to be done differently."

The challenges identified by McAllister in 2005 remain today and are being addressed by several stakeholders. The Council on Academic Accreditation (CAA) in Speech-Language Pathology and Audiology of the American Speech-Language-Hearing Association (ASHA, 2016) provides the option of obtaining hours of direct clinical contact through the use of clinical simulation, which allows learners to obtain a sufficient variety of supervised clinical experiences in different work settings, with different populations, regardless of geographic location The use of simulation is optional, but it is another tool available to develop clinical knowledge and skills. Best practices in clinical simulation in speech-language pathology and audiology have been compiled by experts in a 2018 document published by the Council on Academic Programs in Communication Sciences 
and Disorders (CAPCSD) (Dudding et al., 2018). Included in this comprehensive document is a discussion of simulation-based learning environments (SBLEs), defined by Gaba (2004) as simulation-based learning environments which include techniques to replace or amplify real experiences with guided experiences that evoke or replicate substantial aspects of the real world in a fully interactive manner.

Healthcare SBLEs can be used to train healthcare professionals to perform clinical skills and to work in teams with the goal of improved patient safety (Dudding, et al., 2018; MacKinnon, 2011; Mills et al., 2019). MacBean, Theodoros, Davidson, and Hill (2013), in a paper describing the use of SBLEs in Australian speech-language pathology programs, described perceived advantages to using SBLEs (p. 364). These include: (a) exposure to a wider range of clinical scenarios; (b) the provision of a safe, controlled learning environment; (c) attainment of uniform educational outcomes, despite different rates of trainee progress; and (d) reproducibility of standardized educational experiences, enabling assessment of clinical skills across students on identical scenarios. Theodoros, Davidson, Hill and MacBean (2010) listed perceived disadvantages of SBLEs, which include: (a) reduced complexity of the simulation, (b) the failure to completely replicate a real-life scenario, (c) uncertainty regarding accreditation of SBLEs to establish competency, (d) funding and other resources, (e) suitability of scenarios beyond early stages of learning, and (f) fear that SBLEs may reduce the need for real-world clinical placements. MacBean et al. (2013) reported (p. 367) that their stakeholders in Australia were committed to the development and integration of SBLEs into clinical education curricula and to building an evidence base to support the use of SBLEs in speech-language pathology clinical education. Dzulkarnain, Pandi, Rahmat, and Zakaria (2015) conducted a systematic review of SBLEs in audiology, and described (p. 882) a range of tools, from basic audiometry to advanced tools such as those for auditory brainstem response testing, simulated patients for examination (Dinsmore et al., 2013), and simulated patients for counseling (English et al., 2004). Four studies met minimum review criteria, and three of these reported a positive effect for the use of an SBLE - that is, the SBLE group showed a significantly higher post-training score than groups who learned via other methods or groups who received no training. Dzulkarnain et al. (2015) concluded with caution that SBLE training is an effective tool and can be used for basic clinical audiology training (p. 881).

\section{The Use of Simulation in CSD Programs}

Dudding and Nottingham (2018) recently conducted a U.S. survey of simulation use in 309 ASHAaccredited university programs in communication sciences and disorders. Responses were received from 136 programs, with $51 \%$ reported using some form of simulation in clinical education (p. 71). The most commonly used simulation was the use of standardized patients ( $26 \%$ of programs) followed closely by computer simulations (23\%); decreasingly less common was the use of digitized mannequins, virtual reality, and task trainers. Most programs surveyed indicated that simulations are being used at the graduate level in a variety of academic and clinical education courses. Simulations were most likely to be used to address clinical skills development and assessment. Simulations were also used to remedy the difficulty reported by some programs in finding an adequate number and variety of clinical placements. When questioned about current attitudes and beliefs regarding the use of simulations to enhance students' clinical knowledge and skills, two-thirds of programs reported that there was an overall receptiveness to the use of simulation technology on the part of faculty; three-fourths indicated also that they should increase 
the amount of simulations used in their programs (p. 76). Most programs considered using simulations as part of remediation plans for students struggling in clinical areas. As one survey respondent indicated (p. 76), "the use of simulation allows students to practice before interacting with real clientele."

Dudding and Nottingham's (2018) finding that standardized patients (SPs) are the most-commonly used simulation in CSD programs is encouraging, given the 40-year history of literature supporting the use of SPs in medical education, and the 20-year history and emerging literature supporting their use in CSD education. Standardized patients have been described by Barrows $(1971,1993)$ as typically able-bodied individuals trained to consistently and accurately portray specific emotions, behaviors and disease symptoms, and relay personal history and everyday concerns of patients, family members or others while interacting with students during simulated patient encounters. A diversity of ethnic and cultural backgrounds, gender, and ages can be represented with SPs. After training, SPs are checked for accuracy by an experienced clinician before being used with students. Enhanced experiential learning results from the student having the opportunity to hone skills in a safe and supportive environment. Using SPs guards against the real patient encountering an inexperienced or inadequate clinician (Ryan et al., 2010). It is important to note that SPs are designed to supplement clinical experience - not to serve as a replacement for firsthand experience (Ainsworth et al., 1991).

\section{The Use of SPs For Assessment of Student Competency}

The use of SPs for assessment purposes is motivated by the desire to establish that the student is 'professionally competent' - defined by Epstein and Hundert (2002, p. 226) as, "the habitual, judicious use of clinical reasoning, technical skills, knowledge, communication and emotion in daily practice for the benefit of the individual and community." The use of SPs to assess physical examination and communication skills was reported by Epstein and Hundert (2002) to be one of the three most common forms of assessment used in medical education. The most common type of SP-based clinical assessment is the Objective Structured Clinical Examination (OSCE). Harden and Gleeson (1979) describe the OSCE as 'a timed examination in which medical students interact with a series of simulated patients in stations that may involve history-taking, physical examination, counseling or patient management'. The OSCE requires students to perform specific tasks and demonstrate specific skills and attitudes within a prescribed period in a highly structured encounter (Harden et al., 1975). Clinical competency is assessed based on objective and structured testing through direct observation. Multiple domains of competency can be assessed, including history-taking, physical examination, medical knowledge, interpersonal skills, communication skills, professionalism, data gathering/information collection, evidence-based decision making, patient-centered care, health promotion, and disease prevention. Predetermined performance criteria are scored on a rating scale or checklist by a trained observer, complementing cognitive knowledge testing via traditional paper/pen assessments. It is customary to have clinical faculty, SP educators and SPs themselves provide evaluation of the OSCE. OSCEs may be administered at key times in the educational process - for example, after the completion of a clinical placement. As such, results of an OSCE can provide evaluation of a part of a curriculum and serve as an impetus for its improvement, thus ensuring that students are gaining the clinical skills necessary to provide quality patient care (Zraick, 2004). 


\section{Key Elements of SP Programs}

There are several key elements to an effective SP program (for review, see Norcini and Boulet, 2003). These include: (a) case development, (b) training of SPs, (c) development of the OSCE, (d) procedures for conducting the OSCE, (e) recruitment and training of judges, and (f) measurement and evaluation. [The interested reader is referred to Hill, Davidson and Theodoros (2010) and Zraick (2012) for a thorough discussion of these elements.]. Without question, establishing and maintaining an SP program requires both individual and institutional support, with many universities having dedicated SP programs whose cost is shared among the various participating colleges or individual educational programs (Zraick, 2002).

\section{The Use of Standardized Patients in Communication Sciences and Disorders}

There have been about a dozen published reports to date on the use of SPs in communication sciences and disorders. Most studies utilized adult SPs. Only one study employed an OSCE to assess student competency. Some studies solicited feedback from students, while others did not. A few studies included standardized family members. The sections which follow immediately below describe the studies to date.

\section{The Use of Standardized or Simulated Patients in Speech-Language Pathology}

The first reported use of simulated patients in speech-language pathology was by Edwards and colleagues for their work done in Australia (Edwards et al., 1995). As reported in Edwards, McGuiness and Rose (2000) and later in Edwards and Rose (2008), a woman portraying a 36-year old inpatient with Broca's aphasia was presented to advanced undergraduate students so they could practice their clinical evaluation and counseling skills in small groups. A 'time-out' approach was used, in which students could take a break during the interaction if they had questions of their clinical instructor, or so that the simulated patient could give feedback to the students. The timeout enabled the group to reflect on the process as well as on the content of the interaction as it was happening. No student outcome measures were reported. Edwards et al. (2000) reported that using SPs was, "...a powerful way for students to become aware of and learn to critique their own reasoning"' (p. 266).

Syder (1996) trained actors to portray a person with a voice disorder or a person with a fluency disorder, and these simulated patients interacted with three groups of students at different points in a 2-year Master's degree program. Students interacted with the simulated patients for one hour, both individually and as part of a group consisting of their peers. During their interaction with the simulated patient, students took turns exhibiting skills such as interviewing, giving information, responding to confrontation, and developing a therapy plan. A time-out approach was used. Students reported that working with SPs was a positive experience. This study did not report student competency measures but results of a post-participation questionnaire given to students indicated that the use of the simulated patients facilitated learning. Syder (1996) suggested that it was appropriate to introduce standardized patients in a group context at an early stage of a clinical course and then develop further activities with individual application as students became more experienced (p. 189). 
Zraick, Allen and Johnson (2003) were the first to report the use of an OSCE with students in speech-language pathology. New graduate students interacted with SPs portraying aphasia during an academic semester in which they were enrolled in a class on the diagnosis and management of neurogenic language disorders. The study had three phases, and in the first phase half the students participated in a time-out-based practice session with an SP, while the remaining half did not. The second phase had all students participate in an OSCE designed to assess interpersonal and communication skills in addition to other diagnostic accuracy skills. The OSCE results were alarming in that both groups demonstrated poor interpersonal and communication skills, with no significant difference between groups (p. 237). The findings in the second phase led to a third phase, during which all students received additional didactic lectures and reading material on professional interpersonal and communication skills. At the end of this last phase, a second OSCE was administered and it was reported (p. 237) that all students demonstrated significantly improved interpersonal and communication skills. A post-participation survey revealed that $100 \%$ of the students agreed strongly that using SPs and OSCEs was appropriate, and that nearly $90 \%$ felt that SPs and OSCEs should be incorporated into their future clinical coursework. Zraick et al. (2003) concluded that "...the use of SPs and OSCEs in speech-language pathology is possible, and acceptable to students", (p. 244).

Believability of SPs, and their ability to portray a case reliably, is essential to their effectiveness as a teaching and assessment tool. As stated by Hill, Davidson and Theodoros (2013a, p. 615), "A significant rationale for the inclusion of SPs in clinical programs is their capacity to offer curriculum planners the ability to standardize opportunities for students to develop skills necessary for effective clinical practice." Further, the authors added, "To ensure this intrinsic value of SPs is maximized, curriculum planners need to know that the performance of SPs in interviews and examinations with students is accurate, reliable and consistent." Edwards et al. (1995) and Syder (1996) relied on their expert opinion when deciding if a patient portrayal was adequate. However, they referred to their patients as 'simulated' rather than 'standardized' and they did not describe the extent to which the portrayal was reproduced the same or similarly across multiple interactions. Zraick et al. (2003) described methods for training their SPs and establishing their validity but did not report objective data that the cases were reproducible.

Hill et al. (2013a) were the first to investigate the accuracy, reproducibility and replicability of SPs portraying three scenarios, each as a parent of a child presenting with a speech disorder. Each scenario contained details of key areas typically addressed within a case history interview. The accuracy of SP portrayal of key features of each scenario was scored by an experienced SLP/SP educator, as well as two additional SLPs. SPs were found to have moderate to high levels of accuracy across the three scenarios. It was further reported (p. 614) that overall inter-rater reliability across all scenarios was greater than $80 \%$. Hill et al. (2013a, p. 624) suggested that further investigation of accuracy, reproducibility and replicability of SPs within a larger number and a wider range of interviews and clinical scenarios would provide information that can be used to establish the use of SPs in the clinical education of speech-language pathology students. It is important to note that the SPs utilized by Hill et al. were not portraying a person with a communication disorder, but rather, the family member of such a person. Therefore, they did not have to portray communication disorder symptoms. 
The first study designed solely to examine the believability of SPs trained to portray aphasia was conducted by Wilson (2015) as part of a larger project at the University of Washington, the aim of which was to develop SPs with neurogenic communication disorders for use in teaching medical and nursing students how to communicate with persons with acquired neurogenic communication disorders. Two female SPs were trained to portray a person with non-fluent aphasia, and the believability of their portrayals was rated on a scale of 0-100 (with the higher the number indicating increasing believability; and a rating of 80 targeted as minimum believability). There were two groups of raters: (a) real patients with non-fluent aphasia and (b) family members of patients with non-fluent aphasia. The study also investigated whether the two cases differed in substantial and significant ways. The SPs were trained to portray communication difficulty in the areas of: (a) auditory comprehension, (b) word finding and grammar, (c) reading comprehension, (d) written expression, and (e) use of gestures and body language. A global 'Believability' rating was also obtained. Ratings obtained from both groups of raters were highly variable overall, and they varied across the five behaviors and the believability rating. It was reported (p. 35) that ratings were more variable, and fewer participants felt the SPs were believable, for the behaviors related to auditory comprehension and use of gestures; greater consistency in ratings and higher ratings of believability were reported for the behaviors related to word finding and grammar. It was also reported (p. 34) that across each of the five communication behaviors there was no statistically significant difference between the two SP portrayals. A noteworthy suggestion for similar studies in the future (p. 39) was to examine the feasibility and benefit of using real patients with communication disorders in the training process of SPs and whether or not SPs are able to more accurately portray a communication disorder when they have interacted with someone who has the disorder they are portraying. To date, no such study has been reported.

Building on the work of Wilson (2015), Baylor and colleagues (2017) trained two females without communication impairment to portray persons with non-fluent aphasia and two males without communication impairment to portray persons with dysarthria. The believability of the patient portrayals was rated on a scale of 0-100 (with the higher the number indicating increasing believability; and a rating of 80 targeted as minimum believability). There were two groups of raters: (a) speech-language pathologists (SLPs) and (b) persons with non-fluent aphasia. The SPs portraying non-fluent aphasia were trained to present communication difficulty in the areas of: (a) auditory comprehension, (b) word finding, (c) agrammatism, (d) reading comprehension, (e) written expression, (f) gestures and body language, and (g) general behavior and demeanor. The SPs portraying dysarthria were trained to present communication difficulty in the areas of: (a) speech movements; (b) loudness, intonation and rate; (c) flat affect; (d) written comprehension; and (e) general behavior and demeanor. It was reported (p. 791) that average ratings met the target for the portrayals of the aphasia characteristics of word-finding problems, agrammatism, gestures and body language, and general behavior and demeanor, but not for auditory comprehension. Targets for the portrayals were met for the dysarthria characteristics of speech movements, loudness and intonation, flat affect, and general behavior and demeanor, but not for rate. In summarizing their findings, the authors wrote (p. 800) that, "the targeted believability goals were achieved for most characteristics, and stakeholders provided many positive comments regarding generally strong believability for the overall portrayals of the cases. For most characteristics, there were no significant differences between the two standardized patients trained to portray each role, suggesting that the standardized patients can be trained to portray these characteristics in a manner 
consistent with each other." A robust discussion of the concept and assessment of 'believability' was presented, with suggestions for future research.

In a recent application of the preliminary work done at the University of Washington, Baylor and colleagues (2019) used the SPs in a clinical skills workshop with second-year medical students. The workshop included instruction about different types of communication disorders and communication strategies, followed by practice with SPs portraying different communication disorders, including aphasia. Outcome measures included a knowledge test, ratings of selfefficacy, and evaluation of students' skills when interviewing SPs. It was reported that the medical students demonstrated significant improvements in knowledge, self-efficacy, and use of recommended communication techniques. Future research suggestions included broadening the workshop audience to other healthcare professionals, and to expand the variety of case presentations.

One clinical skill that lends itself to the use of SPs is the interaction with difficult patients and/or family members (Kühne et al., 2018). Bressmann and Eriks-Brophy (2012) report about a student learning experience whose aim was to teach first-year graduate students in speech-language pathology how to manage difficult patients. The SPs were trained to portray different types of interpersonal difficulty (e.g., aggressive behavior, confrontational behavior, manipulative behavior, passive behavior, withdrawal behavior). In three of the five cases the SPs portrayed an adult with a communication impairment, and in the remaining two cases the SPs portrayed the parent of a child with a communication impairment. Scenarios were developed for each case, and students were expected to provide counseling about the difficult behavior. Following the experience, students completed a Likert-scale questionnaire regarding the realism of the SPs, and they also provided written qualitative feedback. It was reported (p. 167) that the majority of students 'Agreed' or 'Strongly Agreed' that the SP performances were realistic. The qualitative feedback indicated that the students valued the experience and that they felt it added to their professional development, and they recommended that the learning experience be repeated for future students.

Standardized patients are sometimes used in conjunction with standardized family members to give students a more complete simulated learning encounter. In Zraick (2004) a study is described in which SPs portraying Alzheimer's disease were used, along with standardized family members, to teach and test new graduate students in three areas: (1) speech screening, (2) dysphagia screening and (3) family conferencing. A particular focus was on professional communication skills. Standardized patients were brought into the classroom as the investigator modeled the skills and competencies desired of students. A colleague facilitated group discussion. The students reported that the instructor's model was very helpful in giving them a "template" for how to interact with the SPs during their individual SP teaching interactions and a later OSCE. The addition of SP family members was also well received, given the population chosen for portrayal. Family members were armed with key questions to ask, and key dialogues were constructed to illustrate the counseling issues inherent in this population. The SP family members also judged the students using competency checklists. Overall, students demonstrated mastery of nearly all the technical and communication skills and competencies targeted. 
Gregg (2015) also proposes the use of standardized family members, with a focus on initial counseling of parents of clients exhibiting early childhood stuttering. As stated (p. 126), "Sharing information with parents about findings, impressions, and reasons for recommendations, and allowing them special time for questions, is a must." Gregg suggests that using a counseling framework such as the one developed by Yairi and Ambrose (2005) could be embedded into the SP training experience. Gregg additionally describes various scenarios and approaches to using SPs and their family members, with many of these like those used by Zraick et al. (2003).

In addition to using SPs in a 'live' setting, they can be videotaped and presented in other learning formats. In Zraick (2004) a study is described which was designed to develop an awareness of professional interpersonal communication skills in undergraduate senior pre-practicum students. Armed with a videotape library of student-SP interactions, select interactions were chosen to illustrate both acceptable and poor examples of key verbal and nonverbal behaviors (e.g., proxemics, tone of voice, mannerisms, etc.). One half of the class watched the clinical vignettes once in class, with the course instructor providing commentary. The other half of the class was given a CD containing a self-directed PowerPoint presentation that contained the lecture material and the clinical vignettes digitized and embedded within. At the end of the semester, all students were required to watch a series of new clinical vignettes in class and identify key behaviors. Students who had learned via the self-directed PowerPoint presentation did better at recognizing and describing the key behaviors.

Hill, Davidson and Theodoros (2013b) investigated speech-language pathology students' perceptions of a foundation clinical skills simulation program incorporating SPs. The investigators surveyed 175 students (undergraduate and graduate) about their perceived level of anxiety and clinical confidence before and after interacting with SPs. Students were also surveyed at the end to learn about their perceptions of the use of SPs as an adjunct to traditional clinical teaching methods. It was reported that all students reported decreased anxiety levels following clinic. Students also reported significantly increased confidence in a range of clinical skills, and they evaluated the SP program positively.

Gutmann (2016) described the use of SPs in pre-service training of graduate speech-language pathology students, as part of the laboratory component of an AAC course. Three unique SP cases were developed which represented patients with complex communication needs who were in need of an AAC device. The students were concurrently enrolled in the didactic portion of the AAC course and were familiar with relevant concepts and terminology. Each student interacted with the three SPs and were tasked with conducting an interview with a view to ascertaining key pieces of information. These included: what the patient identified as their major communication challenge(s) and whether their current physical status warranted consideration of alternate access for use of AAC. There were post-encounter debriefings of both students and SPs. Within two weeks of participating in the study, students completed a brief online survey about their experience. It was reported (p. 45) that students viewed the experience positively and provided helpful feedback for development of future simulations focused on AAC pre-service training.

\section{The Use of Standardized or Simulated Patients in Audiology}


The literature reporting on the use of SPs in audiology is less extensive than that reporting on their use in speech-language pathology, but nonetheless, the studies in this area contribute uniquely to the broader knowledge base about the SPs in general, and their use specifically in the clinical skills development of hearing health professionals. The studies are varied, with some more focused on technical skill development, while others are more focused on professional communication skills. The inclusion of standardized family members is common. Broadly, research in the area of SP use with audiology students often includes reports of students' feelings or responses to using SPs in their clinical training or coursework, with a lesser focus on competency testing.

English and colleagues (2007) were the first to describe the use of SPs in audiology. These investigators developed a tool known as the Audiological Counseling Evaluation (ACE), a checklist designed for use by SPs and faculty raters to evaluate clinical counseling skills in audiology students. A standardized family member was developed to represent the parent of an infant with a diagnosed hearing loss. Ten audiology graduate students were tasked with conducting a "breaking the news" consultation with the parent. Three experienced audiologists evaluated the videotaped counseling skills using the ACE. There was also a post-encounter debriefing session during which each student received feedback from the standardized parent and the faculty rater (Johnson-Russell \& Bailey, 2010). After the simulated counseling session, each student completed a questionnaire to elicit his or her thoughts regarding the overall experience. Students agreed that the encounter helped them identify strengths and weaknesses in counseling and communication. Additionally, they reported that adding this type of simulation experience would very likely be beneficial to other students.

Wilson, Hill, Hughes, Sher, and Laplante-Levesque (2010) used a questionnaire to determine if first-year audiology students enrolled in a 13-week clinical audiology course at a large university felt their interactions with SPs had improved their ability to interact with clients and perform a basic audiometric assessment. Standardized family members and faculty raters participated in a three-hour training session to familiarize themselves with the facilities, equipment, protocols and cases, and also included role playing exercises and training on the methods of student feedback to be used. In Week 8 of the course, students completed their first of two assessments involving the standardized parent and a computer-based audiological simulation. Each student was given 90 minutes to complete the parent interview, 45 minutes to complete the audiological assessment using the computer-based simulation, 15 minutes to share the results with the parent, and 15 minutes to write a clinical report. Each session was videotaped and rated by the faculty judges using a checklist. In Week 9, each student self-rated his or her performance. In Week 10, the course instructor conducted a group feedback session regarding the case. In Week 11, the students conducted a second, different assessment (with a different standardized parent). The follow-up on this second assessment in Weeks 12 and 13 was the same as that conducted for the first case in Weeks 9 and 10. Analyses of the student post-participation survey responses revealed that students reported that their interactions with the standardized parent significantly improved their performance in all areas of client interaction; they also reported that the parents' portrayals of the cases were realistic. Faculty judges also provided feedback, with one stating in part (p. 25), "I think it's good for the students to be assessed in real-life [like] situations like those early in their studies so that any areas for improvement can be identified as soon as possible." Overall, the results of Wilson et al. support the continued investigation of SPs as potential methods of training and assessing audiology students in the areas of client interaction and basic audiometry. 
Tharpe and Rokuson (2010) described their use of SPs in audiology. Scenarios included SPs portraying parents receiving their child's diagnosis of hearing loss, or parents expressing concern about their child receiving a diagnosis of normal hearing even though their child did not pass a newborn hearing screening. Furthermore, students were able to tailor their professional communication to meet the SPs level of understanding. Instructors observed the simulated sessions in real time and then reviewed the recordings with students at a later time. Students also reviewed the recordings online, and they typically provided a self-evaluation that required little comment from the instructor. In addition, the course instructor designed a checklist for the SP to complete following the encounter, with the checklist items based on course objectives.

Naeve-Velguth, Christensen, and Woods (2013), encouraged by the positive responses by students in both English et al. (2007) and Wilson et al. (2010), reported on the observations made by graduate students who had completed a "breaking difficult news" simulated patient experience using an updated version of the ACE (English et al., 2007) as part of a required course in patient counseling. The survey covered areas such as the value of the simulated experience in identifying a student's strengths/weaknesses, the value of debriefing, the overall value of the experience, the value of the experience to future students, and suggestions for specific case scenarios for which simulation would be valuable. The overall results of the survey were strongly positive. It was reported that the majority of students Agreed or Strongly Agreed that their simulated patient counseling session and associated class discussions helped identify their counseling strengths and weaknesses, and that the debriefing after the session provided them with additional instruction. In addition, all students agreed or strongly agreed that the simulated patient sessions were helpful to their learning and that other students would benefit from the experience. In regard to future scenarios, the majority of students supported adding simulations of challenging patients (see also English, 2005). Taken together with English et al. (2007) and Wilson et al. (2010), the results of Naeve-Velguth et al. support the continued use of simulated family members in audiology counseling education for breaking difficult news and suggest a potential value of using simulated patient interactions for training counseling skills in other clinical situations and scenarios.

Dinsmore et al. (2013) expanded on the work of English et al. (2007) and others by describing in great detail the steps necessary to write a case, procedures to determine performance requirements, and the need to develop remediation plans. By way of example, the authors described a case under development in order to evaluate vestibular assessment and patient communication skills. The authors concluded that current methods of determining clinical competence in audiology lack consistency in implementation across programs, and that utilizing SP assessment in audiology education would provide a useful means to evaluate competence in a uniform way. They call upon audiology programs to begin developing and reporting cases that can be shared and used for summative assessment.

Picou and Tharpe (2015) investigated audiology clinicians' perspectives on the use of SPs by surveying two groups of educators: (1) audiologists with student clinical supervisory experience and (2) and program directors; both groups were familiar with the SP methodology. For both focus groups, discussion questions focused on audiology education, particularly as it related to connecting clinical and classroom education, and also, more specifically, on the use of SPs. The transcripts from both focus groups were analyzed for distinct themes. Identified benefits of SPs 
included features of the encounters themselves (standardization, authenticity, and safety), features of the learning experience (student reflection, comprehensive feedback), and also student outcomes (confidence, interpersonal skills). The identified challenges related to investments of time and access to needed resources. It was further reported (p. 10) that the program directors' insights mirrored those of the veteran clinicians. The directors emphasized the potential benefits of SPs primarily for counseling, but generally felt that SP scenarios involving the more technical aspects of audiology, like audiometry or hearing aid fittings, would be less useful. Specifically, the program directors believed SPs could be most useful for teaching active listening, flexible thinking, critical thinking skills, and, again, gaining confidence. Picou and Tharpe (2015) suggested that the inclusion of SPs during training can help the next generation of audiology students confidently transition to clinical placements with improved interpersonal communication, sensitivity, and psychosocial counseling skills. The authors conclude that, "The better students are trained to deliver all audiological services, the better equipped they will be to address all aspects of hearing loss comprehensively, and to help mitigate hearing loss as a public health concern" ( $p$. 11).

Schroy (2015) reported the efficacy of using SPs with graduate students in a simulation scenario in which they were required to inform a parent that their 6-week old child had failed a newborn hearing screening. Each encounter consisted of a standardized parent who expressed a different emotional response to the diagnosis (tearful, contesting, guilty, and overwhelmed), with both the first and last encounters consisting of a tearful response. Students received feedback directly from the parent following three of the encounters, as well as completed a debriefing session with other participating students and an audiologist to discuss their experiences. Ratings of the students' performance, as well as measurements made of video recordings of the encounters, were analyzed to determine changes in behavior from the first encounter to the final encounter. Results indicated that although results were variable across and within students, improvements were made in several areas and students felt the training was worthwhile and valuable.

Two studies by Alanazi and colleagues $(2016,2017)$ reported on the combined use of manikinbased simulations (Gaba, 2004) and standardized family members. Alanazi et al. (2016) investigated the effect of the combined use of standardized parents and a baby simulator on students' self-confidence in their hearing screening and parental counseling knowledge and skills. Graduate students in either the second or third year of their educational program participated, along with four standardized parents and one certified sign language interpreter. Three case scenarios were developed to represent various situations of hearing screening testing. The scenarios were designed to represent diverse cultural and socioeconomic backgrounds and incorporate a variety of emotional responses (e.g., an angry parent, parents from deaf culture experiencing grief, and a parent from Hispanic culture displaying acceptance). To evaluate the students' confidence level in knowledge and skills, all completed pre- and post-event questionnaires and a satisfaction survey of their learning experience. Overall, the pre- and post-simulation event questionnaire revealed a significant improvement in the students' self-rated confidence levels, and that the mean satisfaction level was 4.71 (range $=3.91-5.00$; $\mathrm{SD}=0.30$ ) on a 5-point Likert scale with a rating of 5 representing 'very satisfied.' In a second study one year later, Alanazi and Nicholson (2017) describe the results of a study similar to their initial one, where standardized parents combined with a baby simulator manikin were used to assess students' self-perceptions of clinical 
competency in the technical and counseling domains across three cases. Prior to engaging with the baby simulator and the standardized parent, students completed a pre-training curriculum about newborn hearing screening training and observed 10 hours of neonatal hearing screening as part of their clinical rotations. In addition, students were given the opportunity to practice conducting hearing screening with the baby simulator on their own before the simulation event. After the simulation event, audiology faculty raters and the standardized parent participated in the debriefing sessions. To evaluate the simulation training from the students' perspectives, a post-event evaluation survey was used to elicit feedback about three major components of the simulation training: (a) simulation environment, (b) learning experience, and (c) highlights of the simulation training. It was reported (p. 289) that all students Agreed or Strongly Agreed that the simulation event enhanced their learning experience. Students reported the cases to be realistic, the standardized parents to be realistic, and the debriefing sessions to be helpful. Student suggestions for improvement included enhanced briefing, and more time to prepare for the interactions. A limitation of both studies conducted by Alanazi and colleagues $(2016,2017)$ is that the evaluation process was limited to the students' perspectives on the simulation training components and did not measure professional competencies in any specific area.

\section{A Framework for the Future}

It is clear from the emerging CSD literature that the use of SPs has the potential to enhance existing methods of clinical skills development and competency testing. Simulated patients portraying communication impairment are believable and reproducible and can be used effectively alone or in combination with other simulation modalities. They are accepted by students and clinical educators alike. Certification standards set forth by the American Speech-Language-Hearing Association (ASHA) allow up to 75 clinical clock hours to be obtained via simulation, which can include the use of SPs. Interest in the use of SPs from clinical researchers has slowly but steadily been building since the early speech-language pathology reports by Edwards et al. (1995), Syder (1996) and Zraick et al. (2003), and the early audiology studies by English et al. (2004).

While the use of SPs in CSD is at a nascent stage, future investigators would do well to become familiar with the standards of best practices established by the Association of Standardized Patient Educators (ASPE) (Lewis et al., 2017). ASPE developed the standards to ensure the growth, integrity, and safe application of SP-based educational endeavors. As described in the document (p. 10), the standards are informed by five underlying values: safety, quality, professionalism, accountability, and collaboration. The standards also describe five domains of best practice: safe work environment; case development; SP training for role portrayal, feedback, and completion of assessment instruments; program management; and professional development. Each domain is divided into principles with accompanying key practices that provide clear and practical guidelines for achieving desired outcomes and creating simulations that are safe for all stakeholders. As a foundational document, the standards are a useful guide for CSD researchers as they plan, execute, and report their work.

\section{Future Research Considerations}


Guided by standards of best practice proposed by ASPE as well as the International Nursing Association for Clinical Simulation and Learning (INACSL, 2017), future SP-based research studies in CSD should focus on:

A. Simulated vs. standardized patients. The Society for Simulation in Healthcare (SSH) Healthcare Simulation Dictionary (Lopreiato et al., 2016) and the INACSL Standards of Best Practice: Simulation ${ }^{\text {SM }}$ Simulation Glossary (INACSL Standards Committee, 2016) clearly define these terms. A standardized patient is always a simulated patient, but a simulated patient is not always a standardized patient (Adamo, 2003). This issue is more than a semantic distinction, as the effort required to prepare simulated patients is less than that for standardized patients. Simulated patients may be appropriate if one is going to utilize formative assessment, where the goal is to monitor student learning to provide ongoing feedback that can be used by instructors to improve their teaching and by students to improve their learning. Standardized patients are more appropriate for summative assessment, such as an OSCE or other high-stakes assessment, where the goal is to evaluate student learning at the end of an instructional unit by comparing it against some standard or benchmark.

B. Simulated 'family' members. Given the role that parents or other caregivers play in familycentered care for hearing, speech, voice, cognitive and language impairments in children and adults, efforts should be made to develop clinical simulations that focus on all who are potentially impacted by a patient's communication impairment - this includes not only parents, but siblings, adult children, spouses and other communication partners. The more inclusive term standardized participant is increasingly being used to refer to all human role players in any simulation context (Loprieto et al., 2016).

C. 'Clinical competence'. Scalese and Hatala (2013) have written extensively about competency assessment in healthcare simulation. They emphasize the need to have standardized behavioral criteria when assessing whether a student has demonstrated the ability to perform a specific role or skill in accordance with expectations. Having clearly defined and agreed-upon criteria are important for both formative and summative assessments, particularly so when it comes to a high-stakes simulation-based assessment such as an OSCE.

D. SP training formats. Training prepares SPs to portray roles, give feedback, and complete assessment instruments - skills that are not mutually exclusive. A comparison of the predominant face-to-face format with alternatives, such as online or blended formats, may help refine training according to the learning objectives of the activity, the preferences of the SP educator, and the experience of the SP (Benedict et al., 2017).

E. Debriefing models. All simulation experiences should include a debriefing session, aimed toward reflective thinking. There is a robust nursing literature which describes various models of debriefing as well as guidelines for which models are most effective (see Fisher \& Oudshoom, 2019 for an overview). Given how taxing it is to portray a communication impairment for even a brief period of time, examination of the effect of doing so would help optimize SP recruitment and preparation (Plaksin et al., 2016). Likewise, educators have an ethical responsibility to more fully understand the psycho-emotional impact on students who participate in simulated clinical experiences (Ghadirian, \& Ghiyasvandiyan, 2016).

F. Assessment instruments. There are many types of assessment tools (e.g., checklists, rubrics, narrative feedback) available to SPs and faculty raters, with checklists being predominant in the CSD literature. It may be that something other than a checklist is more ideally suited for a particular learner or learning objective. Because of the importance of professional 
communication in real-world clinical encounters, it is understandable that this area of clinical competency is often a primary focus of CSD research using SPs. Given this, one wonders whether a checklist is adequate to capture the nuances of interpersonal dynamics between a relatively inexperienced student and a person portraying something as complex as a communication impairment (Cömert et al., 2016).

G. Simulation integration into a curriculum. Successful integration of simulation into a curriculum is determined by careful planning and cultivated buy-in on the part of stakeholders (Dudding et al., 2018). Kern, Thomas, and Hughes (2009) identified six steps in curriculum development, beginning with a needs assessment and concluding with program assessment. As Dudding and Nottingham (2018) discovered, only about 1 in 4 CSD academic programs include the use of SPs to teach and assess students' clinical skills, and there was variability in how and when SPs were incorporated. Investigation of barriers to more widespread adoption of SPs is warranted, given the additional finding reported by Dudding and Nottingham (2018) that three-fourths of responding programs indicated that they should increase the amount of simulations used in their programs. One possible study would be to compare student outcomes when the simulation experience occurs concurrently with an academic course versus at the conclusion of a course. Similarly, a study which examines maintenance of skills acquired during a simulation, or the generalization of the skills to other simulated or real-world clinical scenarios, would help establish the validity of SPs as an instructional modality.

SPs in hybrid simulations. Hybrid simulation is defined as the use of two or more simulation modalities to enhance the fidelity of a scenario by integrating the environment, physiology, emotions, and dialog of a real patient encounter (INACSL, 2016). A few studies in audiology have combined SPs with manikins or task trainers, but there are no such reports in speechlanguage pathology. One potential study could combine the use of video laryngoscopy on a high-fidelity manikin in a clinical encounter with a SP. Another example could be to combine the use of an otoscopy trainer with a clinical encounter with an SP. In both examples, the student might be expected to explain to the SP the purpose of the examination and its results.

I. SPs for interprofessional professional education (IPE). The use of SPs for IPE is routinely used in the education of medical students (Blue et al., 2010) and nursing students (Meleis, 2016) as well as in the education of students from allied health disciplines (Schwindt et al., 2017). While IPE has recently begun to receive more systematic discussion and implementation in CSD (e.g., Gurevich et al., 2019; Ludwig et al., 2019; Rosa-Lugo et al., 2017), very few CSD studies have used SPs for IPE (see reviews by Wallace et al., 2017; Zraick et al., 2014). A recent IPE study which used SPs was conducted by Noureddine, Hagge, and Brady (2016), who had an SP who was a stroke survivor portray a person with aphasia, apraxia of speech, and left hemiparesis. This SP presented with swallowing complaints. This SP interacted with prelicensure nursing students in a baccalaureate program and second year speech-language pathology graduate students in a two-phase unfolding case. In Phase I, students from both disciplines received a case report and completed a chart review, and the nursing students completed a physical examination and a dysphagia screening (which the patient failed). The nursing students then referred the patient to the SLP students, who in Phase II, completed a bedside clinical swallowing examination and determined the appropriate dysphagia diet for the patient. A debriefing session was conducted with all students at the conclusion of the learning experience. The investigators collected qualitative and quantitative data from the students regarding their experience participating in the IPE event. It was reported that the experience resulted in the participants' self-reported satisfaction with the simulation design, education 
practices and satisfaction/self-confidence in the student learning processes. Mills et al. (2019) also conducted a simulation-based IPE study which used a stroke-based unfolding case study. Students from speech-language pathology, occupational therapy, and dietetics were shown a series of videos of the patient interacting with professionals from each of the respective disciplines. As described, the first video scenario was utilized to visually reinforce the aspects of the written patient case study, which was provided to participants prior to the workshop. The second video scenario depicted an interprofessional team meeting where clinicians discussed the patient's clinical deterioration and formulated a plan for appropriate assessments and interventions going forward. Video scenario three depicted a clinical handover between team members following positioning and swallowing assessments. The investigators gathered both quantitative and qualitative data to examine students' changes in interprofessional attitudes before and after participation in the learning event. It was reported (p. 2) that attitudes improved, that students liked the structure and format of the workshop, and that they had increased confidence in their ability to practice in interprofessional collaborative practice settings. Another simulation-based IPE study which focused on swallowing disorders was conducted by MacQuillan (2019) who used a validated IPE competency tool to evaluate student skills before and after an IPE simulation lab. The lab included clinical dietetics students and speech-language pathology students, all in their first semester of graduate school. In mixed groups, students used thickened liquids and placed both feeding tubes and speaking valves on simulation mannequins before participating in a group debriefing discussion. Students' posttest and pre-test scores were compared to determine if their self-assessment of competencies changed. It was reported that the item tracking "ability to inform care decisions by integrating the knowledge and experience of other professions appropriate to the clinical situation" (MacQuillan, 2019, p. 56) had the biggest increase in score. Other items with large jumps in score concerned improved communication and effectiveness in interprofessional team-based care.

\section{Conclusion}

The CSD literature to date suggests that inclusion of SPs into a clinical skills program is perceived by faculty and students to be a valuable approach to learning a broad array of clinical skills. As simulated learning environments evolve, and advance in their realism, so will the ways in which SPs are utilized, leading to better student outcomes, and ultimately, more competent patient care.

\section{Disclosures}

The author has no financial or non-financial disclosures.

\section{References}

Adamo, G. (2003). Simulated and standardized patients in OSCEs: Achievement and challenges 1993-2003. Med Teach, 25(3), 262-270.

Ainsworth, M.A., Rogers, L. ., Markus, J.F., Dorsey, N.K., Blackwell, T.A., \& Petrusa, E.R. (1991). Standardized patient encounters. A method for teaching and evaluation. Journal of the American Medical Association, 266(10), 1390-1396. 
Alanazi, A.A., \& Nicholson, N. (2017). Students' evaluation of audiology simulation training. Canadian Journal of Speech-Language Pathology \& Audiology, 41(3), 289-302.

Alanazi, A.A., Nicholson, N., Atcherson, S. R., Franklin, C., Anders, M., Nagaraj, N., Franklin, J., \& Highley, P. (2016). Use of Baby Isao simulator and standardized parents in hearing screening and parent counseling education. American Journal of Audiology, 25, 211-223.

American Speech, Language, Hearing Association (2016). Council on Academic Accreditation in Speech-Language Pathology and Audiology. www.asha.org/Certification/CertificationStandards-for-SLP--Clinical-Simulation/.

Barrows, H.S. (1971). Simulated patients (programmed patients): The development and use of a new technique in medical education. Charles $\mathrm{C}$. Thomas.

Barrows, H.S. (1993). An overview of the uses of standardized patients for teaching and evaluating clinical skills. Academic Medicine, 68(6), 443-451

Baylor, C., Burns, M., McDonough, K., Mach, H., \& Yorkston, K. (2019). Teaching medical students skills for effective communication with patients who have communication disorders. American Journal of Speech-Language Pathology, 28(1), 155-164.

Baylor, C., Burns, M. I., Struijk, J., Herron, L., Mach, H., \& Yorkston, K. (2017). Assessing the believability of standardized patients trained to portray communication disorders. American Journal of Speech-Language Pathology, 26(3), 791-805.

Benedict, N., Smithburger, P., Donihi, A. C., Empey, P., Kobulinsky, L., Seybert, A., Waters, T., Drab, S., Lutz, J., Farkas, D., \& Meyer, S. (2017). Blended simulation progress testing for assessment of practice readiness. American Journal of Pharmaceutical Education, 81(1), 14.

Blue, A.V., Zoller, J., Stratton, T. D., Elam, C. L., \& Gilbert, J. (2010). Interprofessional education in US medical schools. Journal of Interprofessional Care, 24(2), 204-206.

Bressmann, T., \& Eriks-Brophy, A. (2012). Use of simulated patients for a student learning experience on managing difficult patient behaviour in speech-language pathology contexts. International Journal of Speech-Language Pathology, 14(2), 165-173.

Cömert, M., Zill, J. M., Christalle, E., Dirmaier, J., Härter, M., \& Scholl, I. (2016). Assessing communication skills of medical students in objective structured clinical examinations (OSCE) -A systematic review of rating scales. PloS One, 11(3), e0152717.

Dewey, J. (1915). Schools of Tomorrow. Dutton.

Dinsmore, B.F., Bohnert, C., \& Preminger, J. E. (2013). Standardized patients in audiology: A proposal for a new method of evaluating clinical competence. Journal of the American Academy of Audiology, 24(5), 372-392.

Dudding, C.C., Brown, D. K., Estis, J., Szymanski, C., \& Zraick, R. I. (2018). Best Practices in Healthcare Simulations in Communication Sciences and Disorders. Council of Academic Programs in Communication Sciences and Disorders. http://www.capcsd.org/wpcontent/uploads/2018/05/Simulation-Guide-Published-May-18-2018.pdf

Dudding, C.C., \& Nottingham, E. E. (2018). A national survey of simulation use in university programs in communication sciences and disorders. American Journal of SpeechLanguage Pathology, 27(1), 71-81.

Dzulkarnain, A.A.A., Pandi, W. M., Rahmat, S., \& Zakaria, N. A. (2015). Simulated learning environment (SLE) in audiology education: A systematic review. International Journal of Audiology, 54(12), 881-888. 
Edwards, H., Franke, M., \& McGuiness, B. (1995). Using simulated patients to teach clinical reasoning. In J. Higgs, \& M. Jones (Eds.), Clinical Reasoning in the Health Professions. (pp. 269-278).Butterworth-Heinemann.

Edwards, H., McGuiness, B., \& Rose, M. (2000). Using simulated patients to teach clinical reasoning. In J. Higg, \& M. Jones (Eds.), Clinical Reasoning in the Health Professions (2nd ed). (pp. 262-269).Butterworth-Heinemann.

Edwards, H., \& Rose, M. (2008). Using simulated patients to teach clinical reasoning. In Higgs, J., Jones, M.A., Loftus, S., \& Christensen, N. (Eds.). Clinical Reasoning in the Health Professions. (pp. 423-431). Boston: BH Elsevier.

English, K. (2005) AuD students' concerns about interacting with patients and families. School of $\begin{array}{llll}\text { Speech-Language } & \text { Pathology and }\end{array}$ http://ideaexchange.uakron.edu/speech_ideas/179

English K., Kooper R., \& Bratt G. (2004). Informing parents of their child's hearing loss: 'Breaking bad news'. Guidelines for audiologists. Audiology Today, 16, 10-12.

English, K., Naeve-Velguth, S., Rall, E., Uyehara-Isono, J., \& Pittman, A. (2007). Development of an instrument to evaluate audiologic counseling skills. Journal of the American Academy of Audiology, 18(8), 675-687.

Epstein, R.M., \& Hundert, E. M. (2002) Defining and assessing professional competence. Journal of the American Medical Association, 287(2), 226-235.

Fisher, M. E. M., \& Oudshoorn, A. (2019). Debriefing for professional practice placements in nursing: A concept analysis. Nursing Education Perspectives, 40(4), 199-204.

Gaba, D.M. (2004). The future vision of simulation in health care. Quality and Safety in Health Care, 13 (Suppl. 1), i2 - i110.

Ghadirian, F., \& Ghiyasvandiyan, S. (2016). Psycho-emotional impact of simulators in undergraduate nursing education: A systematic review. Health Research Journal, 1(3), 185-195.

Gurevich, N., Osmelak, D. R., \& Farris, C. (2019). Interprofessional education between speech pathology and nursing programs: A collaborative e-platform curriculum approach. Journal of Interprofessional Care, DOI: 10.1080/13561820.2019.1657815

Gregg, B.A. (2015). Academic training in initial counseling of parents of preschoolers who stutter: A simulated caregiver model. Procedia-Social and Behavioral Sciences, 193, 123-130.

Gutmann, M. (2016). Use of simulation with standardized patients in AAC pre-service training: Potentiating practical learning. Perspectives of the ASHA Special Interest Groups, 1(12), 38-44.

Harden, R.M., \& Gleeson, F. A. (1979). Assessment of clinical competence using an objective structured clinical examination (OSCE). Medical Education, 13(1), 39-54.

Harden, R.T.M., Stevenson, M., Downie, W. W., \& Wilson, G. M. (1975). Assessment of clinical competence using objective structured examination. British Medical Journal, 1(5955), 447-451.

Hill, A.E., Davidson, B. J., \& Theodoros, D. (2010). A review of standardized patients in clinical education: Implications for speech-language pathology programs. International Journal of Speech-Language Pathology, 12(3), 259-270.

Hill, A.E., Davidson, B. J., \& Theodoros, D. G. (2013a). The performance of standardized patients in portraying clinical scenarios in speech-language therapy. International Journal of Language \& Communication Disorders, 48(6), 613-624. 
Hill, A.E., Davidson, B. J., \& Theodoros, D. G. (2013b). Speech-language pathology students' perceptions of a standardised patient clinic. Journal of Allied Health, 42(2), 84-91B.

INACSL Standards Committee (2016). INACSL standards of best practice: Simulation ${ }^{\text {SM }}$ Simulation glossary. Clinical Simulation in Nursing, 12(S), S39-S47.

INACSL Standards Committee (2017). INASCL Standards of Best Practice: Simulation ${ }^{\text {SM: }}$ Operations. Clinical Simulation in Nursing, 13, 681-687.

Johnson-Russell, J., \& Bailey, C. (2010). Facilitated debriefing. In Nehring, W.M., \& Lashley, F.R. (Eds.), High-fidelity Patient Simulation in Nursing Education (pp. 369-385). Jones and Bartlett.

Kern, D.E., Thomas, P. A., \& Hughes, M. T. (Eds.) (2009). Curriculum Development for Medical Education: A Six Step Approach. (2nd ed.). Johns Hopkins University Press.

Kühne, F., Ay, D. S., Otterbeck M. J., \& Weck F. (2018). Standardized patients in clinical psychology and psychotherapy: A scoping review of barriers and facilitators for implementation. Academic Psychiatry, 42(6), 773-781.

Lewis, K.L., Bohnert, C. A., Gammon, W. L., Hölzer, H., Lyman, L., Smith, C., Thompson, T. M., Wallace, A., \& Gliva-McConvey, G. (2017). The association of standardized patient educators (ASPE) standards of best practice (SOBP). Advances in Simulation, 2(1), 10-18.

Lopreiato, J., Downing, D., Gammon, W., Lioce, L., Sittner, B., Slot, V., et al. (2016). Healtheare Simulation Dictionary. Available from: http://www.ssih.org/Dictionary. Accessed December 18, 2019.

Lioce, L. (Ed.), Lopreiato, J. (Founding Ed.), Downing, D., Chang, T.P., Robertson, J.M., Anderson, M., Diaz ,D.A., and Spain A.E. (Assoc. Eds.) and the Terminology and Concepts Working Group (2020), Healthcare Simulation Dictionary-Second Edition. Rockville, MD: Agency for Healthcare Research and Quality; January 2020. AHRQ Publication No. 20-0019. DOI: https://doi. org/10.23970/simulationv2.

Ludwig, D. A., Pawl, B., McGraw, S. L., \& Baird, K. (2019). A model of interprofessional education in clinical placements for speech-language pathology and dietetic students. Perspectives of the ASHA Special Interest Groups, 4(2), 279-285.

MacBean, N., Theodoros, D., Davidson, B., \& Hill, A. E. (2013). Simulated learning environments in speech-language pathology: An Australian response. International Journal of SpeechLanguage Pathology, 15(3), 345-357.

MacKinnon, R. (2011). Editorial: The rise of the collaborative inter-professional simulation education network. Infant, 7, 6-8.

MacQuillan, E. (2019). Interprofessional education competency building using simulation: Speech language pathology and dietetics students work together on a dysphagia simulation lab. Journal of the Academy of Nutrition and Dietetics, 119 (9), A56.

McAllister, L. (2005). Issues and innovations in clinical education. Advances in Speech Language Pathology, 7(3), 138-148.

Meleis, A.I. (2016). Interprofessional education: A summary of reports and barriers to recommendations. Journal of Nursing Scholarship, 48(1), 106-112.

Mills, B., Hansen, S., Nang, C., McDonald, H., Lyons-Wall, P., Hunt, J., \& O’Sullivan, T. (2019). A pilot evaluation of simulation-based interprofessional education for occupational therapy, speech pathology and dietetic students: Improvements in attitudes and confidence. Journal of Interprofessional Care, 1-9. 
Naeve-Velguth, S., Christensen, S.A., \& Woods, S. (2013). Simulated patients in audiology education: Student reports. Journal of the American Academy of Audiology, 24(8), 740746.

Norcini, J., \& Boulet, J. (2003). Status of standardized patient assessment: methodological issues in the use of standardized patients for assessment. Teaching and Learning in Medicine, 15(4), 293-297.

Noureddine, N., Hagge, D. K., \& Brady, D. (2016). Developing simulation-based interprofessional education: nursing and SLP students. International Journal of Nursing \& Clinical Practices, 3, 177.

Picou, E., \& Tharpe, A. M. (2015). Standardized patients: Potential to improve student training in aural rehabilitation. Perspectives on Public Health Issues Related to Hearing and Balance, 16(1), 4-14.

Plaksin, J., Nicholson, J., Kundrod, S., Zabar, S., Kalet, A., \& Altshuler, L. (2016). The benefits and risks of being a standardized patient: A narrative review of the literature. The PatientPatient-Centered Outcomes Research, 9(1), 15-25.

Polovoy, C. (2015). Way to grow: What do you do when you have an explosion of undergrads... a huge market demand... and limited training slots with maxed-out trainers? You don't panic. You get to work. ASHA Leader, 20(1), 40-46.

Rosa-Lugo, L.I., Mihai, F. M., \& Nutta, J. W. (2017). Preparation of speech-language pathologists to work with English learners (ELs): Incorporating interprofessional education (IPE) and interprofessional collaborative practice (IPP) competencies. Perspectives of the ASHA Special Interest Groups, 2(14), 103-121.

Ryan, C.A., Walshe, N., Gaffney, R., Shanks, A., Burgoyne, L., \& Wiskin, C. M. (2010). Using standardized patients to assess communication skills in medical and nursing students. BMC Medical Education, 10(1), 24.

Scalese, R., \& Hatala, R. (2013). Competency assessment. In Levine, A. I., DeMaria, S., Schwartz, A. D., \& Sim, A. (Eds.), The Comprehensive Textbook of Healthcare Simulation (pp. 135160). New York: Springer Publishing.

Schroy, C. (2015). Counseling Training for Audiology Students: Using Standardized Patients. (Unpublished doctoral dissertation). Washington University. Arts \& Sciences Electronic Theses and Dissertations. 563. https://openscholarship.wustl.edu/art_sci_etds/563

Schwindt, R., Agley, J., McNelis, A. M., Hudmon, K. S., Lay, K., \& Bentley, M. (2017). Assessing perceptions of interprofessional education and collaboration among graduate health professions students using the Interprofessional Collaborative Competency Attainment Survey (ICCAS). Journal of Interprofessional Education \& Practice, 8, 23-27.

Syder, D. (1996). The use of simulated clients to develop the clinical skills of speech and language therapy students. European Journal of Disorders of Communication, 31(2), 181-192.

Tharpe, A.M.M. \& Rokuson, J. M. (2010). Simulated patients enhance clinical education: Vanderbilt offers unique program for audiology students. ASHA Leader, 15(10), 5-6.

Theodoros, D., Davidson, B., Hill, A., \& MacBean, N. (2010). Integration of simulated learning environments into speech pathology clinical education curricula: A national approach. Health Workforce Australia; https://www.hwa.gov.au/sites/uploads/slesin-speechpathology-curricula-201108.pdf. 
Wallace, S.E., Manspeaker, S. A., \& Matthews, L. (2017). Interprofessional education: A literature review and suggestions for implementation with older adults. Perspectives of the ASHA Special Interest Groups, 2(15), 3-8.

Wilson, L. (2015). Evaluating the Believability of Standardized Patients Portraying Aphasia. (Unpublished master's thesis). University of Washington.

Wilson, W.J., Hill, A., Hughes, J., Sher, A., \& Laplante-Levesque, A. (2010). Student audiologists' impressions of a simulation training program. Australian and New Zealand Journal of Audiology, 32(1), 19-26.

Yairi, E. \& Ambrose, N. G. (2005). Early Childhood Stuttering for Clinicians by Clinicians.ProEd.

Zayyan, M. (2011). Objective structured clinical examination: The assessment of choice. Oman Medical Journal, 26(4), 219.

Zraick, R. (2002). The use of standardized patients in speech-language pathology. Perspectives on Issues in Higher Education, 5(1), 14-16.

Zraick, R.I. (2004). Playacting with a purpose: Using standardized patients to assess clinical skills. ASHA Leader, 9(10), 22-22.

Zraick, R.I. (2012). Review of the use of standardized patients in speech-language pathology clinical education. International Journal of Therapy and Rehabilitation, 19(2), 112-118.

Zraick, R.I., Allen, R. M., \& Johnson, S. B. (2003). The use of standardized patients to teach and test interpersonal and communication skills with students in speech-language pathology. Advances in Health Sciences Education, 8(3), 237-248.

Zraick, R.I., Harten, A. C., \& Hagstrom, F. (2014). Interprofessional education and practice: A primer for training future clinicians. Division 10 Newsletter, 17(2), 39-46. 